\title{
BODIES OUT OF PLACE: BLACK QUEER STUDENTS NEGOTIATING IDENTITY AT THE UNIVERSITY OF CAPE TOWN
}

\author{
F. Boonzaier* \\ e-mail: Floretta.Boonzaier@uct.ac.za
}

\section{Mhkize*}

e-mail: liindamkhize@gmail.com

*Department of Psychology

University of Cape Town

Cape Town, South Africa

\section{ABSTRACT}

The issue of racial identity and belonging appears to be foregrounded in current struggles around the decolonisation of higher education in South Africa. However, current debates about belonging as well as critiques of the masculinist nature of sectors of the student movement have drawn stark attention to the complexities of subjectivity. Intersectional subjectivities have been highlighted. This article attends to the narratives of seven black queer students and their negotiations of identity at an historically white university in South Africa amid struggles around decolonisation. We employ the Photovoice method where participants produce photo-narratives around their identities as black queer persons. Our analysis reveals not only the extent to which participants' experiences illustrate their struggles around belonging in a space not historically "theirs" but also the extent to which their narratives are potentially transformative and challenge representations of them and their lives.

Keywords: black queer students, LGBTIQ+ students, university cultures, heteronormativity

\section{INTRODUCTION}

Issues of racial identity and belonging appear to be foregrounded in current struggles around the decolonisation ${ }^{1}$ of higher education in South Africa. However, these contestations around belonging, alongside activist debates around the masculinist nature of sectors of the student movement have drawn attention to the complexities of intersectional subjectivities. Sectors of the student activist movement have focused on the intersectional nature of their experiences at South African universities. Yet, the extent to which this has been highlighted in academic engagement on transformation is questionable. That universities are masculinist, patriarchal institutions has been established. However, how these environments create an unwelcoming space for $\mathrm{LGBTIQ}+{ }^{2}$ persons and others outside of the normative, binary framework of 
sexuality and gender is not always given sufficient attention - in academic discourse and university policy/practices.

In the context of dealing with the aftermath of colonialism and apartheid in SA, higher education institutions have been an important site for discussions about transformation (Kessi 2013) and more recently, decolonisation. However, most of these discussions are centered on race and gender to ensure that the demographics of the students/staff match those of the larger South African populace. Recent transformation efforts at South African universities have ensured that queer ${ }^{3}$ students are potentially more visible or better represented in student populations. Despite this emphasis on visibility, queer persons are still forced to navigate overtly heterosexist and heteronormative institutions both internationally and in South Africa (Ellis 2009; Rankin 2003). A study that examined the quality of life (QOL) for LGB (lesbian, gay and bisexual) students from Cuba, Norway, India and South Africa, found heterosexual students in all countries rated their QOL higher than queer students (Træen, Martinussen, Vittersø and Saini 2009). Furthermore, the more accepting the culture was towards homosexuality the higher LGB students rated their QOL. It appears most campus cultures are not accommodating towards queerness because of overt heterosexist acts as well as heterosexist micro-aggressions and policies that do not acknowledge LGBQ students' needs (Brown, Clarke, Gortmaker and Robinson-Keilig 2004). Heterosexism is "an ideological system that denies, denigrates, and stigmatizes any non-heterosexual form of behaviour, identity, relationship or community” (Herek 1990, 316). Therefore, heterosexism seeks to enforce traditional gender roles by normalising negative attitudes towards anyone who disrupts stereotypes of conventional gendered behaviour (Herek 1986).

Overt heterosexist acts on campuses take the form of physical violence and verbal threats (Ellis 2009; Evans and Broido 2002) while heterosexist micro-aggressions displayed through deliberate exclusions, subtle put-downs, or deliberately ignoring queer individuals (Silverschanz, Cortina, Konik and Magley 2008). These "indirect” (but still harmful) forms of discrimination are common on university campuses and difficult to monitor (Ellis 2009). Particular attention has been paid to university residences and their inherently homophobic nature (Graziano 2004; 2005; Hames 2007; Msibi and Jagessar 2015; Rankin 2003). This research highlights queer students' experiences of psychological, verbal and physical assault and a lack of support services. These findings suggest deep-seated institutional cultures of heteronormativity in higher education settings and highlight how these spaces are not exempt from the challenges and prejudices that constitute wider society. LGBQ students may choose to stay silent and invisible by not disclosing their sexual orientation and purposefully changing 
their behaviour and dress to avoid discrimination and harassment (Ellis 2009).

\section{TRANSGENDER ${ }^{4}$ STUDENTS IN HIGHER EDUCATION}

Transgender persons are usually invisibilised under the LGBTIQ+ umbrella, which means their concerns are inadequately accounted for. Still, their experiences are worthy of consideration as a separate issue (McKinney 2005). Research on transgender students in higher education is an emerging field with limited literature that focuses solely on trans persons (McKinney 2005). Within SA, there appears to be almost no research focused solely on trans students. However, the international literature indicates that university campuses are not safe spaces for trans individuals as they experience multiple types of marginalization, high discrimination and victimisation (Bilodeau 2009; Garvey and Rankin 2015; Seelman 2014). These include, but are not limited to (a) being questioned within or prevented from entering residences/bathrooms on campus (Bilodeau 2007; Seelman 2014); (b) being sexually assaulted, bullied and harassed because of their gender identity and/or expression (Rankin 2003; Bilodeau 2007); (c) lack of recognition of trans-diverse persons on campus (Bilodeau 2007); (d) administrative procedures (record adjustments, applications, forms) do not acknowledge gender fluid or non-binary identities (Bilodeau 2007); (e) an absence of curricula, knowledge and proficiency among staff/faculty about transgender issues and how to support trans students (Rankin 2003; McKinney 2005); (f) lack of resources to address trans/gender identity issues and counselling/health facilities are ill-equipped to help trans students (McKinney 2005); and (g) a deficiency of transgender support groups (McKinney 2005).

Seelman (2014) argues that the above experiences and challenges are the result of “institutional cisgenderism” defined as "the behaviours, goals, norms, and values of higher education institutions that reflect an underlying assumption or belief that cisgender identities are more 'normal', 'healthy', and 'real' and therefore are treated as 'superior' to transgender and gender non-conforming identities,” (Seelman 2014, 619-620). These entrenched patterns and ways of thinking result in the consistent privileging of cisgender students and the invisibility or oppression of trans-diverse students (Seelman 2014). Discussing “institutional cisgenderism” highlights how discrimination against trans students goes beyond interpersonal interactions and resides in the invisible power structures of the gender binary systems in campus classrooms, admissions offices, employment procedures, LGB organisations, residences/ bathrooms (Bilodeau 2007). These challenges and experiences are taking place within higher education settings that have committed themselves to "transformation”, "diversification” and “accessibility” by creating numerous policies and appointing special task teams (Ahmed 2012). 
However, such institutional procedures are clearly not enough to implement real life changes and are sometimes used as a replacement for actual action (Ahmed 2012).

Alongside the lack of accommodations outlined above, the exclusions faced by queer and trans students intersect with other dynamics related to their identities. While these intersectional oppressions have not been given sufficient attention, we know that higher education, is a generally difficult and stressful experience for black students because, "there are deep problems virtually everywhere within the system” (Soudien 2008, 668).

\section{THE "BLACK ${ }^{5}$ EXPERIENCE" IN HIGHER EDUCATION}

The "black experience" in higher education may be summed up through the interlinked areas of racialising discourses around transformation, symbolic exclusions, and the experiences of poor, black students.

One of the central mechanisms of higher education transformation is affirmative action policies. These policies have effectively increased the number of students of colour; however, they have also been met with intense backlash. This backlash has taken the form of discourses of reverse racism and lowered academic standards, which construct black students as undeserving of their place at university (Daniels and Damons 2011; Kessi and Cornell 2016). Within these discourses black students are seen as lacking the attributes necessary to succeed and only being present to fulfill a quota in the university (Daniels and Damons 2011; Kessi and Cornell 2016). They are constructed as “the problem” rather than as young people claiming their right to education (Kessi 2013).

Such discourses have real life consequences for black students. Internationally (JohnsonAhorlu 2012; Harper 2009; 2013; Phoenix 2009) and locally research (De Beer, Smith and Jansen 2009; Higham 2012) shows how these narratives are internalised by black students which may lead to low self-esteem, alienation and potentially impact academic performance negatively. These narratives have made students question their abilities and the validity of their place at university (Daniels and Damons 2011; Kessi and Cornell 2016). Young black women from Stellenbosch University explained how such spaces make them feel like they are seen solely for their racial identity and not just as students (Daniels and Damons 2011). Similarly, black students at UCT commented that when they arrived at university it was the first time that they "felt black" due to the negative narratives surrounding them (Kessi and Cornell 2016). “Feeling black” as opposed to "being black” narrates how other people perceive black students as a result of racialized transformation discourses (Kessi and Cornell 2016). Due to these perceptions, black students felt that white students did not see them as academic equals and 
thus their contributions to group work were undermined and challenged; they were not favoured as work partners, and other students were shocked when they excelled academically (Kessi and Cornell 2016).

Another emerging theme in the literature about black students' experiences in higher education is that of symbolic exclusion. This involves a lack of names, icons, symbols, practices and discourses that acknowledge and reflect the existence of a diverse student body (Daniels and Damons 2011). Such problems were brought to attention two years ago with the \#RhodesMustFall (\#RMF) movement where students mobilised to remove the statue of Cecil John Rhodes at UCT because of its glorification of colonialism and representation of institutionalised racism and sexism. Failing to have cultural artifacts and symbols that recognize the presence of black students, universities create spaces that only affirm white student identities. Therefore, black students' success in these spaces is determined by the ability to assimilate into whiteness (Kessi and Cornell 2016) or mimic the invisible norm (Puwar 2001). In the work by Kessi and Cornell (2016), students also stressed the white, western-centric curriculum and the scarcity of black academics, citing the importance of issues of representation. Curriculum content is important, as the degree to which students can relate to the material plays a role in the quality of their learning experience and in increasing their knowledge and skills (Hickling-Hudson and Ahlquist 2003). These issues highlight how universities are still controlled by a dominant institutional culture of whiteness which contributes to institutionalised racism (Steyn and Kamper 2011). These practices form through cultural, historical and social forces and place the experiences of white students above those of black students (Kessi and Cornell 2016). The outcome of this is that students of colour are made to feel like a "tolerated otherness" (Daniels and Damons 2011, 148) or as "space invaders" (Puwar 2001).

Considering how race and class are closely intertwined in South African society, black students' experiences of racialised exclusion intersect closely with ideas about class. Poor students attempting to complete a university education while sometimes having to support families face additional burdens and are likely to drop out (Letseka and Maile 2008). The social stigma and unjustified shame around poverty also means that students who are struggling financially hide their difficulties and are more likely to drop out than reveal their situation (Firfirey and Carolissen 2010). Poor South African students express feelings of "otherness" and being "less than" (Firfirey and Carolissen 2010, 996) as well as being constantly reminded of their poverty while interacting with wealthy students (Kessi and Cornell 2016). In this way, "feeling poor" is an extension of "feeling black" and contributes to feelings of otherness, 
exclusion and inadequacy.

The above discussion shows how there is an explicit contrast between the master narratives of "transformative" and "inclusive" university policies/legislation and the lived experiences of black, queer, and transgender students. It is not surprising then that within the last three years South African universities have experienced an eruption of mass student protests against the problems discussed here. Such mass action is the inevitable response to systemic and epistemic injustices and violence and thus greater attention needs to be given to the ways in which certain groups of students are excluded physically and symbolically.

In this article, we attend to the narratives of seven black queer students and their negotiations of identity at an historically white institution amid current struggles around decolonisation. We locate the article in the growing body of work on belonging and alienation in South African higher education. We specifically ask the question: What stories do black queer students construct around their negotiation of subjectivity in university spaces?

\section{THEORETICAL FRAMEWORK}

We approach this work from an intersectional, black feminist perspective that foregrounds gendered power together with other forms of oppression. Intersectionality is founded on the idea of the interconnections between multiple experiences and identities. It foregrounds black feminist theorizing of gender oppression and how it is imbricated with racism, classism and other forms of inequity. Collins (2000) describes the intersecting identities and experiences of oppression as a matrix of domination, referring to the "overall social organization within which intersecting oppressions originate, develop, and are contained” (2000, 228). The matrix of domination illustrates how multiple forms of oppression shape and influence each other, and work as a system of oppression. Intersectionality is a useful framework, not only for the analysis of the ways in which power works to shape the experiences of black queer students, but also to analyse how these experiences might be transformed.

\section{METHOD}

We employed the Photovoice method in which participants produce photo-narratives about identities as black queer individuals. Photovoice is a participatory research process that allows participants to use photography to identify and represent the social issues that are relevant to their lives or communities (Wang and Burris 1997). Group discussions about these photographs encourage critical conversations, knowledge production and consciousness-raising about pertinent issues affecting the group and the process can generate change and affirmation (Wang and Burris 1997). 


\section{SAMPLING}

Seven participants who volunteered to participate in the study were interviewed about their experiences at the university. Participants (see Table 1 for the demographics) were recruited from UCT by advertising through a student research participation programme in the Psychology department and RainbowUCT (LGBTQI+ group on campus). Of these seven participants, four produced photo-narratives that further elaborated on their experiences. Four participants also participated in a focus group discussion where they shared their stories and experiences of inclusion/exclusion related to their identities. All the participants were from UCT because we explored how the university culture/environment influenced how they negotiated their gendered and sexual identities. Although students chose to foreground their discussions of sexuality, issues of gender identity emerged too, especially for the two students who identified as transgender.

Table 1: Sample demographics

\begin{tabular}{|l|l|l|l|l|}
\hline Pseudonym & Age & $\begin{array}{l}\text { Preferred } \\
\text { Pronouns }\end{array}$ & Gender & Sexual Orientation \\
\hline Redi & 20 & She/Her & Cisgender woman & Bisexual \\
\hline Pam & 20 & She/Her & Cisgender woman & Bisexual/Lesbian \\
\hline Pumeza & 21 & $\begin{array}{l}\text { He/Him OR } \\
\text { They/Them }\end{array}$ & $\begin{array}{l}\text { Trans* Agender6 } \\
\text { (does not identify } \\
\text { themselves as having a } \\
\text { particular gender) }\end{array}$ & $\begin{array}{l}\text { Panromantic } \\
\text { (person romantically attracted } \\
\text { to others but not limited by } \\
\text { others sex or gender) }\end{array}$ \\
\hline Yoliswa & 19 & They/Them & $\begin{array}{l}\text { Trans* Non-binary } \\
\text { (does not identify } \\
\text { themselves as having a } \\
\text { particular gender) }\end{array}$ & $\begin{array}{l}\text { Pansexual } \\
\text { (capable of sexual attraction to } \\
\text { any gender) }\end{array}$ \\
\hline Busi & 21 & She/Her & Cisgender woman & Pansexual \\
\hline Gcina & 24 & She/Her & Cisgender woman & Bisexual \\
\hline Bulelwa & 22 & She/Her & Cisgender woman & Queer \\
\hline
\end{tabular}

\section{DATA COLLECTION}

Photovoice is a relatively new method and without a fixed process (Malherbe, Cornell and Suffla 2015). This flexibility allowed us to use Photovoice in a way that best suited the study.

The research process began with individual interviews. We were interested in hearing about how participants spoke about their gendered/sexual identities and how these identities were negotiated in the spaces they occupied. Interviews were semi-structured to allow a multitude of topics to be explored and for participants to talk about whatever they felt was relevant. After the initial interview, participants were given cameras and taught how to use them to capture the images they wanted in their photo-stories. Participants were then given a photo mission that asked them to take photographs that represented their lives as queer black people at UCT. 
After a few weeks, participants returned with their photographs to share in a focus group setting. Here, participants shared their photographs with the group and found similarities as well as differences with each other. This group setting helped facilitate a discussion and collaborative narration of stories around the topic at hand. The use of individual interviews, focus groups and photo-stories was necessary in order to gain a layered understanding of the participants' experiences by using multiple mediums for data collection. Although a photo exhibition had been planned, this was not possible because the university had been shut-down for much of the second semester of 2016 - the year the research was conducted.

\section{DATA ANALYSIS}

We read participants' personal and visual narratives to gain insight on the broader operation of power at an institution like UCT and to understand individual engagement with broader social, political and ideological projects (Kessi and Boonzaier 2017). We used thematic narrative analysis (Riessman, 2008) that involved, in the first instance, a coding of the data for the exploration of emerging patterns. While analyzing these patterns, we were interested in the kinds of narratives participants produced about their experiences, the implications these had for subjectivity and the ways in which they implicated power relations. We see the potential of narrative analysis, specifically for revealing the complexities of subjectivity and for its ability to recognise the importance of intersectionality. We were also eager to highlight the complexity and nuance of participants' experiences and move away from discourses of victimhood and pathology (Msibi and Jagessar 2015). Furthermore, we wanted to explore the potential of narrative for providing the space for oppressed groups to "speak back" to dominant, stigmatizing narratives about them and their lives (Zway and Boonzaier 2015).

We discover three key and intersecting narratives about the ways in which queer black students navigate the university. These are: narratives about the idea of the university, narratives about bodies out of place/space, and stories of struggle.

\section{THE UNIVERSITY AS FREEDOM}

Telling stories about negotiations of identity in the space of a university involves telling about experiences prior to university and negotiations with family, friends, religious and educational institutions and authorities. Heteronormative, gender disciplining (Msibi 2012) in schools occurs through enforcing silence around gendered and sexual expressions as well as disciplining dress (Zway and Boonzaier 2015). Below, Yoliswa articulates the disciplining practices (and their challenging of it) at their former high school, a place they describe as “oppressive”. 
“... girls need to dress like girls and boys need to dress like boys and like we started getting a formalised uniform in and they were like all girls skirts like no question, and I was like HELL NO” (laughing). [Yoliswa].

For Yoliswa, and for others who had experiences that silenced them and their identities or where family or friends reacted negatively to their gender or sexual expressions, the idea of the university was important. This idea of the university involved it being constructed as a place of freedom of identity expression and a place where their identities would be accepted. Pam illustrates this idea below by contrasting her repressive religious background with her expectations about what coming to university might mean.

“Uh, I uhm I come from a very strict background, very religious parents I've got and uh, I was raised as a Jehovah's Witness and that has been very difficult for me since first year. I've been experiencing problems with regard to my sexuality and the homophobic spaces I've been uh, uh I've been in uh in UCT so uh. When I came, when I first came to varsity I thought okay I'm finally gonna come out, because I saw the pink closet thing (a public exhibition by RainbowUCT) on TV one time. I thought: 'aaah this is great! I'm finally gonna get to be myself'.” [Pam].

Redi, similarly expressed the sense of anticipation about coming to university by saying: “... by the time I reached matric I was very eager to get to university and meet girls ...”. She further elaborates on the idea of the university as a space of freedom through the photograph from her photo-story below.

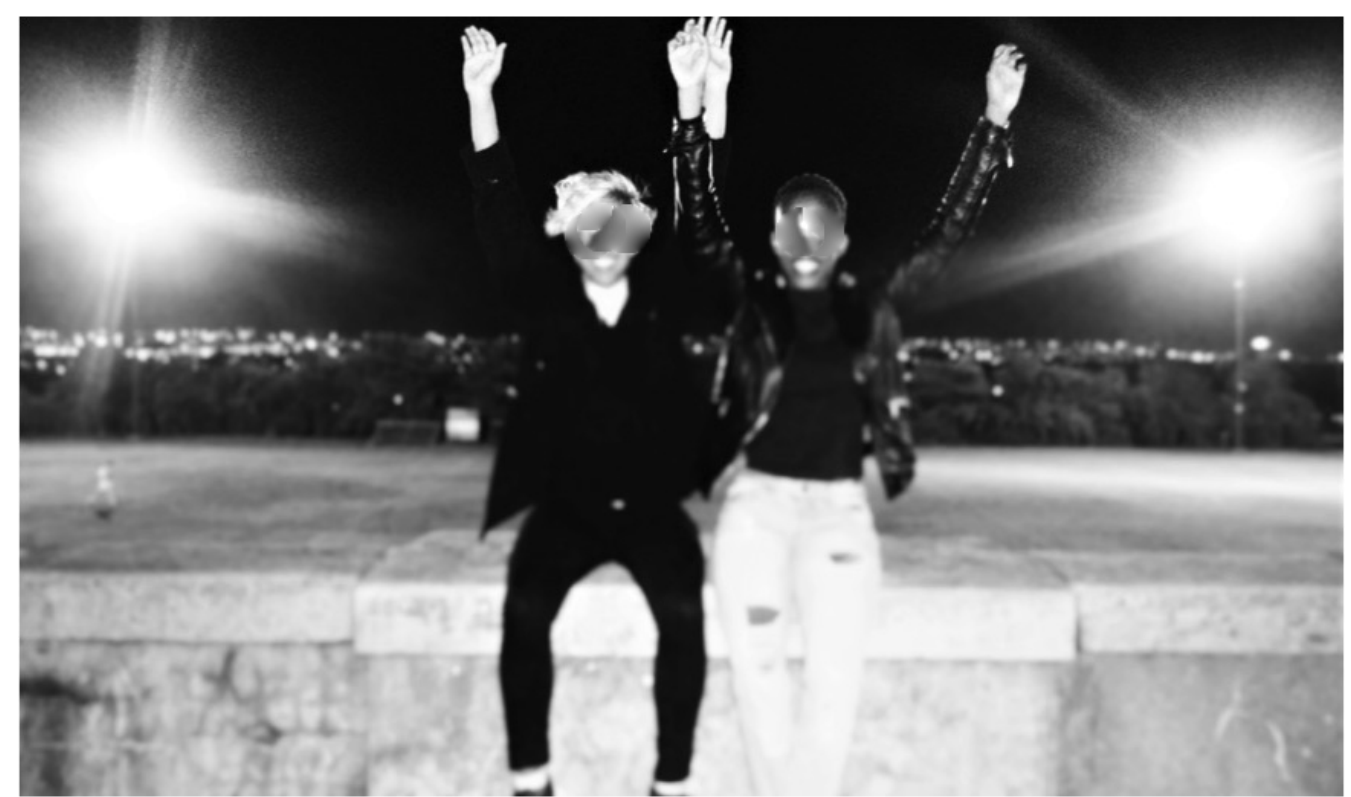

Photo 1: I am proud. I am Free. I am a bisexual woman Photo credit: Redi

In Photo 1, Redi attempts to convey a narrative of "freedom" in the university context. She also communicates a story about the joy and pride she experiences in her identity as a bisexual 
woman. Indeed, some participants spoke about how, to some extent, the university space allowed them to express their gendered and sexual identities in ways that were "more free" than their previous, home, family, school, community or religious contexts.

At the same time, however, this narrative about the university as a space of freedom coexisted precariously with stories about black queer bodies' “out-of-placeness" at the university.

\section{NARRATING BODIES OUT OF PLACEISPACE}

Participant narratives reveal how the idea of the university as a space of freedom is slowly eroded as it comes to be revealed as a space in which them and their bodies are not considered to be the "somatic norm”. By “somatic norm”, Puwar $(2001,652)$ refers to “... the corporeal imagination of power as naturalized in the body of white, male, upper/middle-class bodies”.

“... I don’t want to say I was completely out about me being bisexual, even in high school, but when I got here (UCT) I felt the need to hide it more.” [Bulelwa]

In Bulelwa's photo story she contrasts her expectations about the university with her actual experiences. In Photo 2 she reiterates the idea of the university as a symbolic space of freedom.

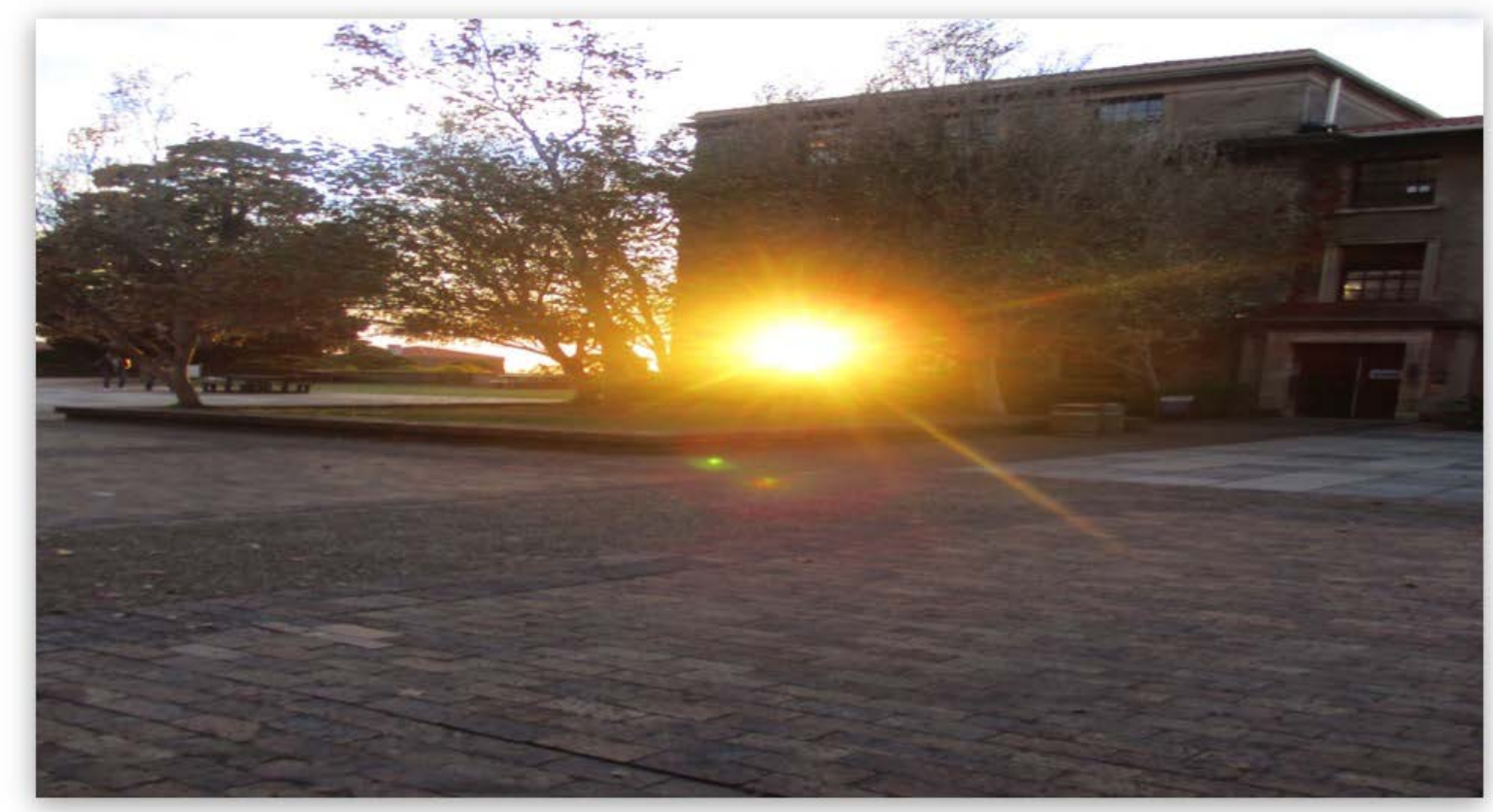

Photo 2: From societal isolation and uncomfortable conversations, campus was a symbol of a new dawn. A calmer and more welcoming experience

Photo credit: Bulelwa

This idea of a "more welcoming" space is contrasted by the second image from Bulelwa's 
narrative. In her presentation of the images in the focus group discussion, she deleted the word "renovations" from the image and replaced it with the following phrases: "your time of transition”, "our time of selfishness where we have completely disregarded your existence” and "your stay here". Her edits to the photograph of the sign at a construction site on the campus was thus meant to reflect the following statements:

"We apologise for the inconvenience caused during your time of transition."

"We apologise for the inconvenience caused during our time of selfishness where we have completely disregarded your existence.”

"We apologise for the inconvenience caused during your stay here."

These statements by Bulelwa, profoundly illustrate the extent of her experiences of alienation, invisibility and out-of-placeness at the institution in which she is not considered "the norm".

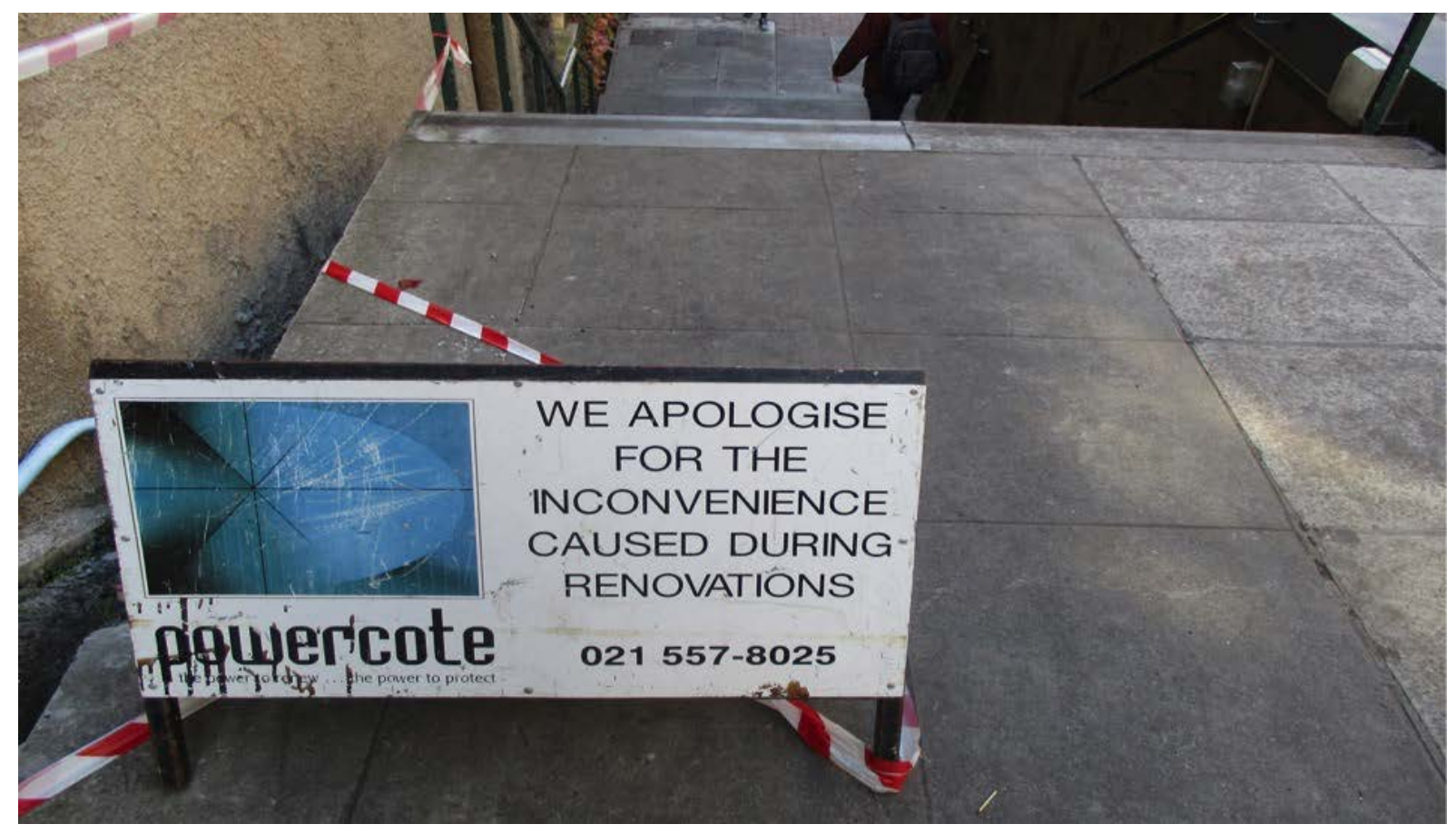

Photo 3: We apologize for the inconvenience caused during your stay here Photo credit: Bulelwa

Bulelwa elaborates on her point about the need to hide her identity by citing her interpersonal encounters with individuals (including friends) who lived in university residences. Other participants shared similar difficulties of living and navigating residence life as queer black persons. These experiences include interpersonal discriminatory encounters and encounters that illustrate the heteronormativity of the residence space and culture, as illustrated in the extract from Yoliswa’s interview below. 
“... okay so with things that happen at UCT there's a lot of events, like huge big events, I sometimes, like most of the time I don't attend them because they're like, if I go to the white-ish parties, like if I'm just not accepted in that sphere. But even in like a party in Kopano (male university residence) there'll be a whole lot of cis and like straight people and they're just gonna be like what are you doing here? And I remember one like really intense thing was like Baxter lawns there was like a poetry like creative night and this one woman went up and she did an amazing rap and people were like 'yaaas this is amazing' and then afterwards she was like 'and guys I'm very proud to be a lesbian' and everyone was like (gasp) and I was like guys you were just clicking and stuff why is it changing now that she has said she's a lesbian? That was like whaaaat! And uhm, other than the misogyny that like men wow, sometimes in those spaces I just feel like I'm not safe and I would just rather hang out with my friends and not in like the UCT (inaudible) and also like people will be willing to have a discussion about race, but as soon as you bring up sexuality they're like what is that or why should we talk about it and why is it important and like who cares about trans people and like but we are having the same discussion, this is like, people who are oppressed, can you not just change it to a different subject, why is it now like completely different thing." [Yoliswa].

Not only does Yoliswa provide commentary on how their identity as someone who describes themselves as "gender fluid", "queer" and "pansexual” is not accommodated in university space and culture, they also foreground the importance of intersectionality for ensuring that the interconnectedness of different oppressions are recognized. Mirroring longstanding black feminist debates, Yoliwa indicates how conversations about particular kinds of exclusions (i.e. racialised) are more tolerated than others. Yoliswa's narrative also echoes an important point around contemporary student struggles at the university. The \#RMF movement, that once described itself as intersectional, foregrounded important struggles around racialised exclusion at UCT. In March 2016, at the first anniversary of the protest action that garnered the momentum for the movement to take hold, the UCT TransCollective disrupted a photographic exhibition of \#RMF to draw attention to the contrast between political rhetoric (specifically intersectionality) and everyday, lived politics and its implications (see Omar 2016). In their public statement of the disruption, they highlighted how trans bodies, while at the forefront of the \#RMF movement, were silenced and excluded at key moments and especially in relation to how the exhibition was curated.

The importance of an intersectional undertaking for examining queer students' experiences of university spaces is further articulated in the extract below from Pam's interview. Pam talks about finding a safe space where her identity as a lesbian can be affirmed. She describes the LGBTIQ organization on campus as a place where she is "free to be" herself and talk about her sexuality without judgement. However, Pam's background in poverty, related schooling experiences and use of language complicates her comfort in the space, as she describes below in response to the interviewer's question about her understanding of the term "intersectionality”. 
“[...] That's one thing that bothers me a lot in my life and that probably why I haven't, that, not probably, definitely why I haven't dated in a long time, because uh at UCT first of all, I'm black, I come from a poor background, I don't speak English that is as fluent as everyone else in UCT and I may not have typical body type that everyone prefers, well you know, so uhm yes, that uhm really disappointed me to find out that such, such, there's, uhm I would be hindered by those things in terms of dating, and uhm yah, in terms of dating and approaching someone that I am interested in because uhm I felt I'm very uhm scared of rejection and that has happened a lot to me in the past, so I I because I couldn't make sense of WHY it was happening, why people were rejecting me because I, I didn't think there was anything wrong with me, I was happy with myself, but coming here I realised that, ukuthi ohhhh maybe people are not interested in me because I'm not as, fluent in English, I'm not eloquent, I'm not uhm, you know and also I, that caused me to withdraw a lot, to to to just lock myself up in my room and not interact with people. I felt like uh ah I don't fit in and uhm even at Rainbow, sometimes, I don't interact with everybody, I interact with only the individuals that I feel comfortable around because I don't want to be judged because someone once said at Rainbow 'that one of my criteria for dating is that the person must speak a certain way', and they said this in a group discussion. They said that they must speak a certain way, if you don't speak good English and you don't have a certain accent, then I'm sorry. So those are the things that make me feel like I wasn't good enough and uhm also because a lot of people at UCT they dress nicely and have nice clothes and I can't, obviously can't afford to to buy swaggy clothes, I can't dress that nice so that makes it hard for me to approach people that I'm interested in because I think, okay I'm not good enough. And I also found that girls are quite picky in the lesbian community and that was a very disappointing thing and it did, it did uhm uhm like, have a negative impact on my self-esteem and self-confidence, it dropped [...] I've been rejected by a lot of people I was really interested in and I couldn't think of other reasons than the fact that those people went to Model C schools, I didn't speak good English so they they so free, they don't even realise their privilege, they so cos they fit in, I don't fit in so, because of that a lot of people find me boring, and sometimes it's not because I don't have much to say, I'm boring (inaudible) it's just that I'm afraid that I will say something wrong and make grammatical errors and that I, that will embarrass me and so people think I'm boring and they don't know the real me and I feel like they reject me because I don't tick the boxes or I don't fit the criteria ....” [Pam].

Although lengthy, it is worth providing the full extract from Pam's interview as it illustrates the complications around belonging, especially in "inclusive” spaces, like the campus LGBTIQ organisation. Pam's sense of alienation comes from her distance to the somatic norm of white, middle/upper class, heterosexual, cisgender, English-speaking, man, not only in her identity as bisexual but also because of her poor background and her supposed "mastery" of the English language. Both Puwar (2001) and Phoenix (2009) illustrate, drawing on the work of Fanon (1986), how language and the use of language serves a powerful assimilative and symbolic function, associated with the "success of civilisation". Pam's narrative also powerfully illustrates, “a painful site of negotiation and contestation over representations” (Phoenix 2009, 109). Pam demonstrates the shame associated with her forms of expression through suggesting that people potentially perceive her as "boring". Though she does not fully articulate it, she amplifies the association between the use of language and assumptions about in/capacity especially at UCT where English is the medium of instruction. 
Participants explicitly described the culture of the institution as heteronormative, illustrating that they and their bodies are seen as "out of place". They provide content to the idea of a heteronormative institutional culture by providing examples from departments, faculties and university infrastructure like the provision of restrooms that only accommodate male and female bodies.

“Hhmmm ... I'll say there's and air of preservation of heteronormativity in - I'm in humanities, that's my faculty. [...] But like what they study like the sample they always use is like male and female, male and female. The bathrooms are male and female. The residences are separated as the male side and the female side. You know what I am saying? The sports are done like, male sports, female sports. Uummm ... It's just ... It's very ...” [Interviewer: 'Binary']. "Binary! It's very binary. And then when you find yourself in the middle of that, it's kind of like, you don't have a facet for yourself to be asserted because nothing represents you.” [Busi].

The institution's heteronormative nature is further illustrated through two photographs in Pumeza’s story.

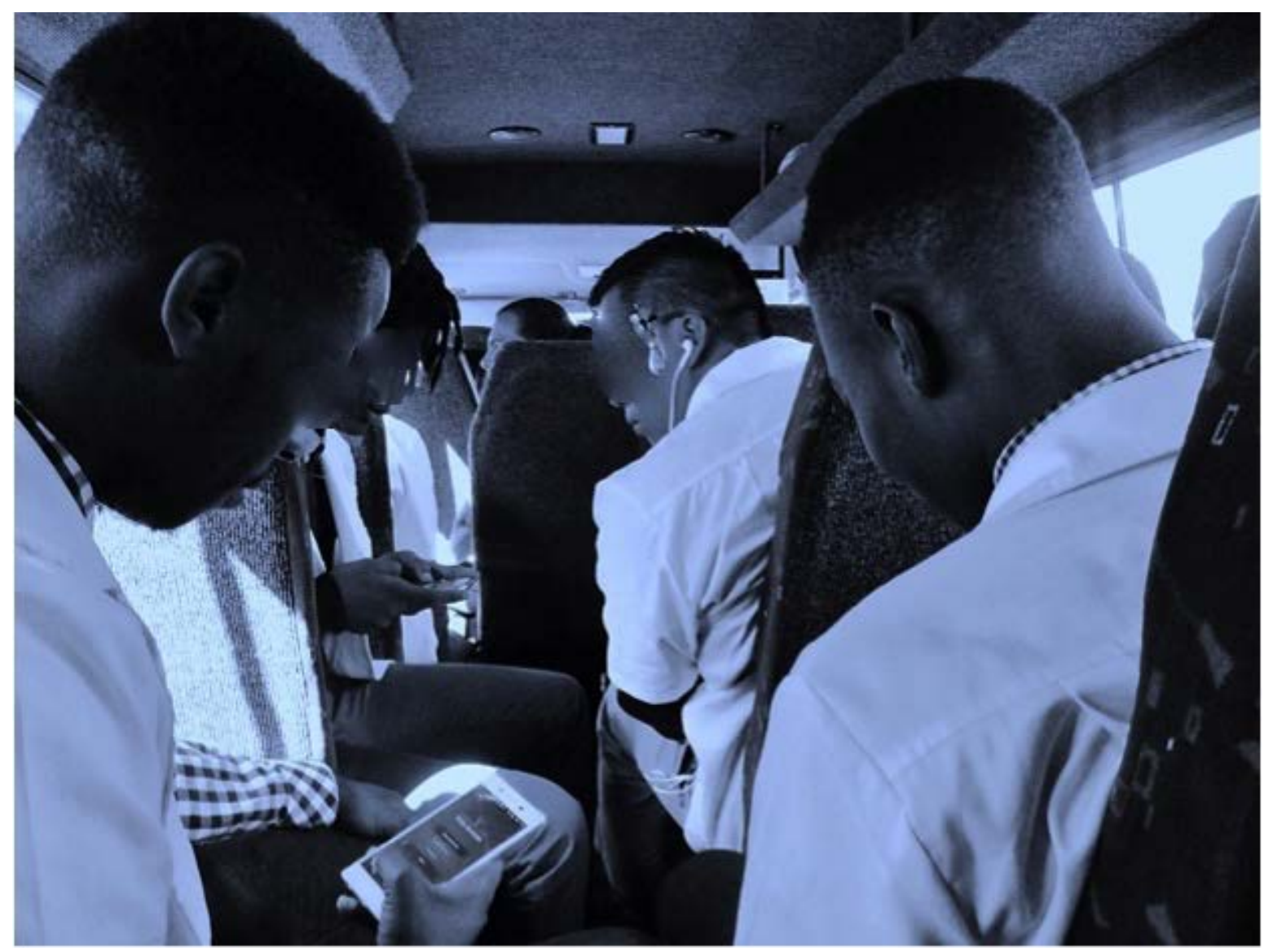

Photo 4: The field/faculty i am in has historically been dominated by men. even in this day and age womxn and afab gnc folk (who are read as womxn) are still subjected to the patriarchal hierarchy that is rampant

Photo credit: Pumeza 


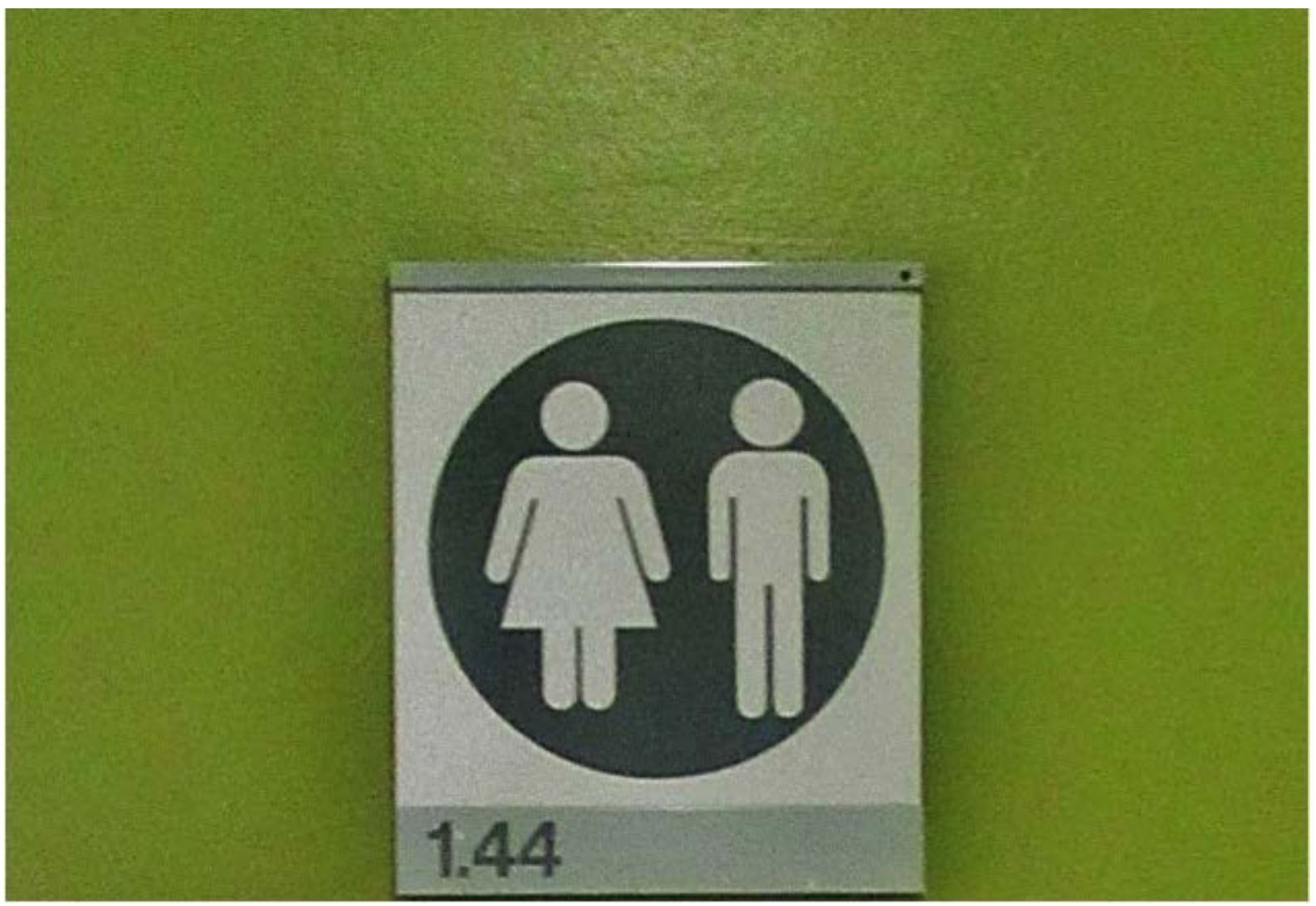

Photo 5: A filthy little slice of heaven

(explanation: tucked away in a corner at the very end of a building no-one ever goes in is this little gem. it's tiny, with just a toilet and a basin quashed into the space of a broom cupboard, dark, dingy, and doesn't smell all too great but even so, it's less of a jarring experience for me to use than sex designated toilets)

Photo credit: Pumeza

\section{ALL OPPRESSIONS ARE CONNECTED: STORIES OF STRUGGLE}

At the time of writing, South African universities were amid a resurgence of student protests demanding free, decolonized education. These protests were sparked to challenge racialised exclusion at historically white institutions like UCT. Despite contestations, or perhaps because of it, this generation of student protestors reflect a keen awareness of the interconnectedness of different oppressions and struggles, as Angela Davis (2016) reminds us in her book that connects struggles from Ferguson to Palestine. The protest movement has reflected broader concerns that include the rights of outsourced workers at UCT, the rights of school-going children, and challenges to institutional complacency regarding sexual violence on campus. Yoliswa's photo story profoundly captures interconnectedness of struggles and speaks to how the encounter with systemic and epistemic violences and the interpellation of people as subjects into relations of gendered and racialised power has the potential to compel a process that may foreground subjects' capacity for struggle and their agency (Phoenix 2009). Reminiscent of the participants in Kessi and Cornell's (2016) study, Yoliswa talks about how they came to their blackness, despite their upper-middle class background, through protest involvement at UCT 
and what it means for them to be black in a space in which white, middle/upper class, heterosexual, cisgender men are the somatic norm (Puwar 2001). They capture this profoundly in their image (Photo 6) from student protest action involving an art installation on campus.

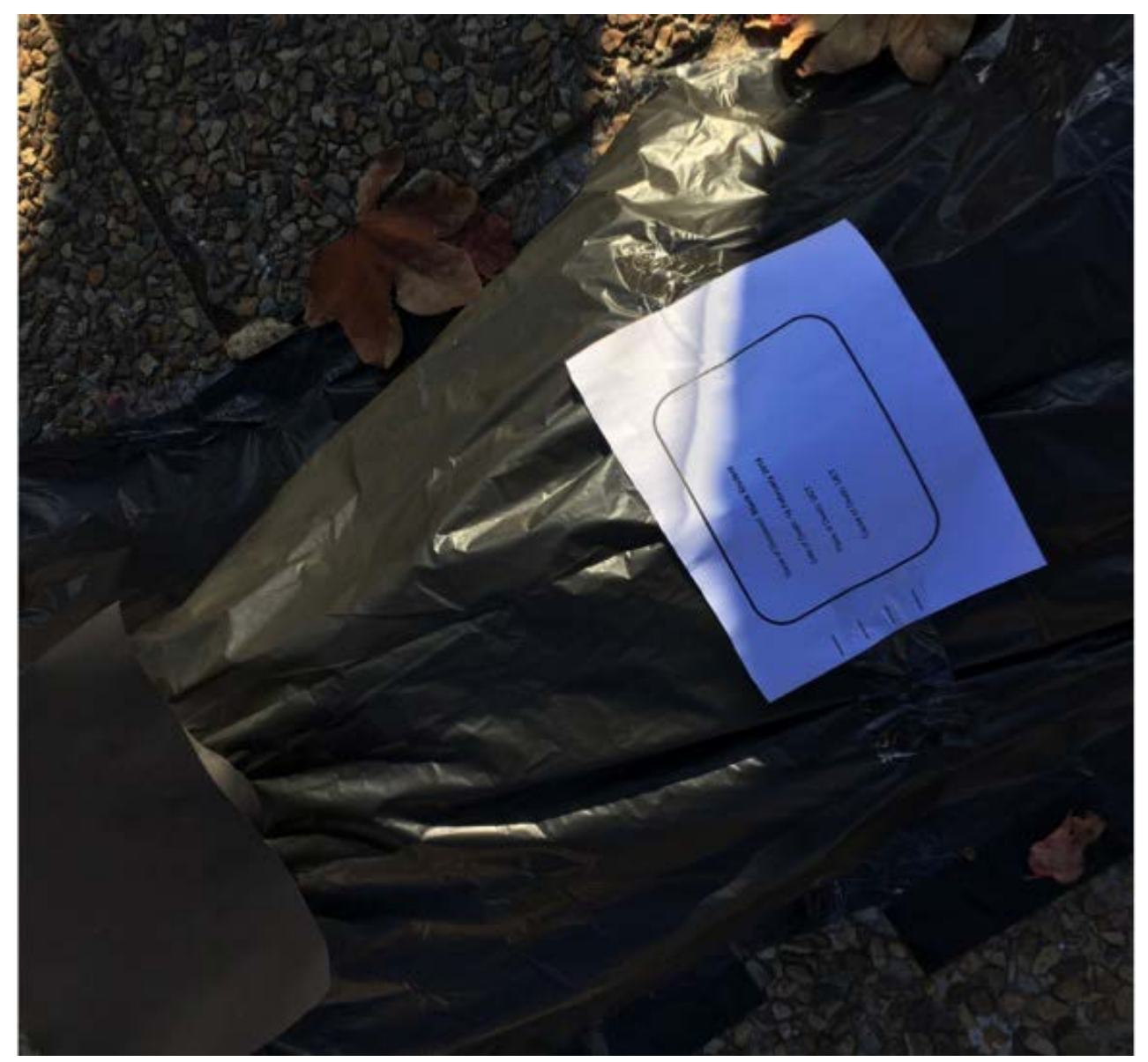

Photo 6: Name of deceased: Black student

Place of death: UCT

Cause of death: UCT

"And suddenly I feared my future at the university."

Photo credit: Yoliswa

Yoliswa describes their coming to protest action in the focus group discussion as follows:

"I had never been involved in protest before [...] I was just watching it first, I was like being an anthropologist look at my journal and like ... and then I was just like, why am I being this person who feels like they need to sit in their privilege and like just write in the book when those are students just like me. These are my friends. What am I doing standing on the outside, looking in and pretending like I am not as affected as them? So I went in and we danced, we sang songs. Yoh, my Xhosa is bad but, like, I managed. I got I got through and it was, actually it was great. That feeling of togetherness. And standing together towards something. It was spectacular really.” [Yoliswa]. 
Yoliswa later talks about their subjectivity as black and queer and how this creates awareness of others' oppressions, which prompted their involvement in protest action to advance the rights of black workers at the university. They articulate this below:

"As a UCT student, you come to quickly learn that there is oppression caused by UCT that goes beyond your immediate self, and that to dismantle the system, you need to approach the system via all angles. Which is why the discussion (about worker's rights) was important to me as a black student.” [Yoliswa].

Yoliswa illustrates the processes through which they are inserted as subjects into relations of racialised, classed, gendered, heteronormative and cisgendered power not only produce subjugation and internalization of these oppressions but simultaneously involves struggles and contestations that foreground their agency and their potential to counteract their experienced oppressions (Phoenix 2009). Talking about "togetherness" and solidarity in the student protests tells us something about the capacity for "bodies out of place" to build communities in institutions that marginalized them.

\section{CONCLUSION}

In this article we examined the intersectional experiences of black queer students at an institution where white, middle/upper class, heterosexual, cisgender men are considered to be the invisible norm. We showed how, despite evidence that institutions across the country are "diversifying” their student bodies, such diversity is not sufficient to address practices and cultures that render particular bodies "out of place".

Students' narratives illustrate the importance of an intersectional reading for understanding how their experiences at university may be complicated by their gendered or sexual identities, and further intermingled with race and class. This is especially important for showing how particular spaces that have been created for LGBTIQ+ groups continue to reproduce exclusions by reflecting the white, middle/upper class practices and cultures of the institutions themselves.

Finally, we illustrate how black queer students, far from internalizing the oppressions they are forced to encounter, engage in collective action and struggle to challenge institutional practices but also to create spaces of belonging in an alienating environment.

\section{ACKNOWLEDGEMENTS}

This work is based on research supported by the National Research Foundation (NRF) of South Africa. Opinions expressed and conclusions arrived at are those of the authors and are not necessarily to be attributed to the NRF. 


\section{NOTES}

1. We understand decolonisation as a process that goes beyond transformation, which could be interpreted as an additive approach to ensuring "representation" and dealing with the legacy of apartheid in South Africa. Decolonisation however, is argued to be a recognition and analysis of the enduring legacies and afterlives of slavery, imperialism, colonialism, apartheid, neocolonialism and neo-liberalism (Ndlovu-Gatsheni, 2013) and attempts to overcome it (Lugones, 2010). We use the term transformation when it has been described as such by authors whose work we cite.

2. While the LGBTQI+ acronym is used widely, LGBTQI+ persons are not a homogenous group and the various identities within the acronym have vastly different needs and life experiences. This is given that the LGBQ part of the acronym deals with sexual orientation whereas the "Tl" parts relate to gender and sex.

3. We use the term "queer" to refer to persons who identify themselves as such but also in reference to any person who identifies as anything other than heterosexual (e.g. lesbian, gay, bisexual, pansexual, asexual, same-gender loving etc.) or cisgender.

4. The term "transgender" refers to any person who identifies as anything other than cisgender (e.g. transmasculine, transfeminine, genderqueer, gender non-conforming, gender fluid, androgynous, two-spirit, third sex etc.) (Garvey and Rankin, 2015; Seelman, 2014).

5. We use the term "black" to refer to all historically oppressed groups in SA as a result of apartheid legislation and practices.

6. The terms used to identify participants' gender and sexual orientation are descriptors used by participants. We also used participants' own definitions of these terms.

\section{REFERENCES}

Ahmed, S. 2012. On being included: Racism and diversity in institutional life. Durham, NC: Duke University Press.

Bilodeau, B. L. 2007. Genderism: Transgender students, binary systems and higher education. Unpublished doctoral thesis. Michigan State University.

Bilodeau, B. L. 2009. Genderism: Transgender students, binary systems and higher education. Saarbrücken, Germany: Verlag Dr. Müller.

Brown, R. D., B. Clarke, V. Gortmaker and R. Robinson-Keilig. 2004. Assessing the campus climate for gay, lesbian, bisexual and transgender (GLBT) students using a multiple perspectives approach. Journal of College Student Development 45(1): 8-26.

Collins, P. H. 2000. Black feminist thought: Knowledge, consciousness, and the politics of empowerment. $2^{\text {nd }}$ Edition. New York, NY: Routledge.

Daniels, D. and L. Damons. 2011. "I am more than just a coloured woman” - Narrating undergraduate experiences at a historically white South African university. Africa Education Review 8(1): 148168.

Davis, Angela Y. 2016. Freedom is a constant struggle : Ferguson, Palestine, and the foundations of a movement, ed. Frank Barat. Chicago, IL: Haymarket Books.

De Beer, J., U. Smith and C. Jansen. 2009. "Situated” in a separated campus - students' sense of belonging and academic performance: A case study of experiences of students during a higher education merger. Education as Change 13(1): 167-194.

Ellis, S. J. 2009. Diversity and inclusivity at university: A survey of the experiences of lesbian, gay, bisexual and trans (LGBT) students in the UK. Higher Education 57: 723-739.

Evans, N. J. and E. M. Broido. 2002. The experiences of lesbian and bisexual women in college residence halls. Journal of Lesbian Studies 6: 29-42. 
Firfirey, N. and R. Carolissen. 2010. "I keep myself clean ... at least when you see me, you don't know I am poor": Student experiences of poverty in South African higher education. South African Journal of Higher Education 26(6): 987-1002.

Garvey, J. C. and S. R. Rankin. 2015. The influence of campus experiences on the level of outness among trans-spectrum and queer-spectrum students. Journal of Homosexuality 62: 374-393.

Graziano, K. J. 2004. Coming out on a South African university campus: Adaptations of gay men and lesbians. Society in Transition 35(2): 273-286.

Graziano, K. J. 2005. Reflections from university students in a South African gay and lesbian society. International Journal for the Advancement of Counselling 27(2): 299-310.

Hames, M. 2007. Sexual identity and transformation at a South African university. Social Dynamics 33(1): 52-77.

Harper, S. R. 2009. Niggers no more: A critical race counternarrative on black male student achievement at predominantly white colleges and universities. International Journal of Qualitative Studies in Education 22(6): 697-712.

Harper, S. R. 2013. Am I my brother's teacher? Black undergraduates, racial socialization, and peer pedagogies in predominantly white postsecondary contexts. Review of Research in Education 31(1): 183-211.

Herek, G. M. 1986. On heterosexual masculinity: Some psychical consequences of the social construction of gender and sexuality. American Behavioural Scientist 29: 563-577.

Herek, G. M. 1990. The context of anti-gay violence: Notes on cultural and psychological heterosexism. Journal of Interpersonal Violence 5: 316-333.

Hickling Hudson, A. and R. Ahlquist. 2003. Contesting the curriculum in the schooling of indigenous children in Australia and the United States: From Eurocentrism to culturally powerful pedagogies. Comparative Education Review 47(1): 64-89.

Higham, R. 2012. Place, race and exclusion: University student voices in post-apartheid South Africa. International Journal of Inclusive Education 16: 485-501.

Johnson-Ahorlu, R. J. 2012. The academic opportunity gap: How racism and stereotypes disrupt the education of African American undergraduates. Race, Ethnicity and Education 15(5): 633-652.

Kessi, S. 2013. Transforming historically white universities: Students and the politics of racial representation. New Agenda: South African Journal of Social and Economic Policy 50.

Kessi, S. and J. Cornell. 2016. Coming to UCT: Black students, transformation and discourses of race. Journal of Student Affairs in Africa 3(2): 1-16.

Kessi, S. and F. Boonzaier. 2017. Resistance and transformation in postcolonial contexts. In The social psychology of everyday politics, ed. C. Howarth and E. Andreouli, 116-130. London: Routledge.

Letseka, M. and S. Maile. 2008. High university drop-out rates: A threat to South Africa's future. Human Sciences Research Council Policy Brief.

Lugones, M. 2010. Toward a decolonial feminism. Hypatia 25(4): 742-759.

McKinney, J. S. 2005. On the margins: A study of the experiences of transgender college students. Journal of Gay and Lesbian Issues in Education 3(1): 63-75.

Ndlovu-Gatsheni, S. J. 2013. Decolonising the university in Africa. The Thinker 51: 46-51.

Malherbe, N., J. Cornell and Suffla. 2015. Taking pictures, telling stories and making connections: A photovoice manual. Johannesburg, South Africa: Institute for Social \& Health Sciences. University of South Africa.

Msibi, T. 2012. "I'm used to it now": Experiences of homophobia among queer youth in South African township schools. Gender and Education 24: 515-533.

Msibi, T. and V. Jagessar. 2015. Restricted freedom: Negotiating same-sex identifications in the residential spaces of a South African university. Higher Education Research and Development 34(4): 750-762. 
Omar, Y. 2016. Trans Collective stops RMF exhibition. Monday Paper, University of Cape Town. http://www.uct.ac.za/dailynews/?id=9620 (Accessed 29 October 2016).

Phoenix, A. 2009. De-colonising practices: Negotiating narratives from racialized and gendered experiences of education. Race, Ethnicity and Education 12(1): 101-114.

Puwar, N. 2001. The racialised somatic norm and the senior civil service. Sociology; SOC 35(3): 65170.

Rankin, S. R. 2003. Campus climate for gay, lesbian, bisexual, and transgender people: A national perspective. New York, NY: National Gay and Lesbian Task Force Policy Institute.

Riessman, C. K. 2008. Narrative methods for the human sciences. Los Angeles, CA: Sage.

Seelman, K. L. 2014. Recommendations of transgender students, staff, and faculty in the USA for improving college campuses. Gender and Education 26(6): 618-635.

Silverschanz, P., L. M. Cortina, J. Konik and V. J. Magley. 2008. Slurs, snubs, and queer jokes: Incidence and impact of heterosexist harassment in academia. Sex Roles 58: 179-191.

Soudien, C. 2008. The intersection of race and class in the South African university: Student experiences. South African Journal of Higher Education 22(3): 662-678.

Steyn, M. G. and G. D. Kamper. 2011. Barriers to learning in South African higher education: Some Photovoice perspectives. Journal for New Generation Sciences 9(1): 116-136.

Træen, B., M. Martinussen, J. Vittersø, and S. Saini. 2009. Sexual orientation and quality of life among university students from Cuba, Norway, India and South Africa. Journal of Homosexuality 56: 655-669.

Wang, C. and M. A. Burris. 1997. Photovoice: Concept, methodology, and use for participatory needs assessment. Health education \& behavior 24(3): 369-387

Zway, M. and F. Boonzaier. 2015. "I believe that being a lesbian is not a curse”: Young black lesbian women representing their identities through photovoice. Agenda: Empowering women for gender equity 29(1): 96-107. 